\section{Commentary: Surgery for an anomalous aortic origin of a coronary artery: To do, or not to do? That is the question}

\author{
Phillip S. Naimo, MD, , a, , \\ Edward Buratto, MBBS, PhD, ${ }^{\mathrm{a}, \mathrm{b}, \mathrm{c}, \mathrm{d}}$ and \\ Igor E. Konstantinov, MD, PhD, FRACS ${ }^{\mathrm{a}, \mathrm{b}, \mathrm{c}, \mathrm{d}}$
}

\begin{abstract}
Management of asymptomatic patients with anomalous aortic origin of a coronary artery (AAOCA) (Figure 1) is a dilemma that has been tormenting surgeons and physicians alike for decades. Does the risk of surgery in asymptomatic patients outweigh the risk of sudden death? What is the risk of sudden death? Will we ever know the true risk of sudden death in the general population with unknown incidence of AAOCA? Despite feverish discussions of the topic at multiple meetings, the research addressing these questions is limited. Will these questions ever be answered?

Clearly, the true incidence of sudden death is difficult, perhaps even impossible, to establish. It has been reported that AAOCA is the second most common cause of sudden death, ${ }^{1-3}$ with a rate of 0.6 deaths $/ 100,000$ people, albeit in competitive young athletes. Although AAOCA of a right coronary artery is 6 to 10 times more common than AAOCA of a left coronary artery, it appears that AAOCA of the left coronary artery has a slightly higher risk of sudden death. ${ }^{4,5}$ Brothers and colleagues ${ }^{1}$ calculated a cumulative risk of death over a 20-year period in people aged 15 to 35 years with AAOCA participating in competitive sports to be $6.3 \%$ for AAOCA of the left coronary artery and $0.2 \%$ for
\end{abstract}

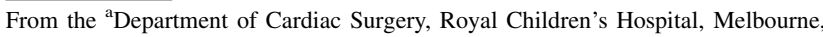
Victoria, Australia; ${ }^{b}$ Department of Paediatrics, University of Melbourne, Melbourne, Victoria, Australia; ${ }^{c}$ Heart Research Group, Murdoch Children's Research Institute, Melbourne, Victoria, Australia; and ${ }^{\mathrm{d}}$ Melbourne Centre for Cardiovascular Genomics and Regenerative Medicine, Melbourne, Victoria, Australia.

Disclosure: Authors have nothing to disclose with regard to commercial support.

Received for publication Feb 4, 2020; accepted for publication Feb 6, 2020; available ahead of print Feb 14, 2020.

Address for reprints: Igor E. Konstantinov, MD, PhD, FRACS, Royal Children's Hospital, Flemington Rd, Parkville, VIC 3052, Australia (E-mail: igor. konstantinov@rch.org.au).

J Thorac Cardiovasc Surg 2020;160:772-3 0022-5223/ $\$ 36.00$

Crown Copyright (C) 2020 Published by Elsevier Inc. on behalf of The American Association for Thoracic Surgery

https://doi.org/10.1016/j.jtcvs.2020.02.017
}

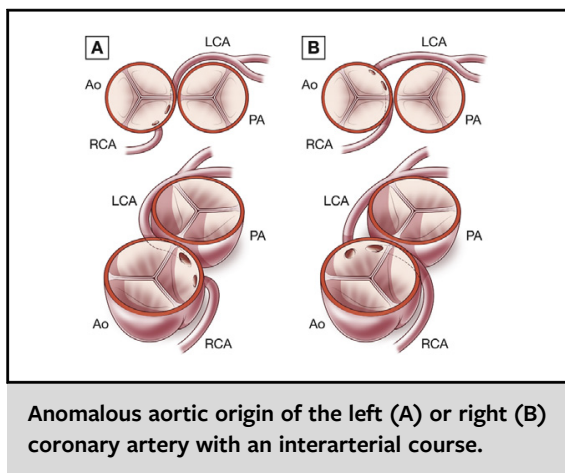

CENTRAL MESSAGE

The role of surgery, despite its

low risk, in asymptomatic pa-

tients with AAOCA is unclear.

right coronary artery. One would expect that the incidence of such events should be lower in the general population compared with competitive athletes.

Given that these studies of AAOCA have been performed in competitive athletes, the true incidence of sudden death in the general population due to AAOCA is unknown. Even less is known about the incidence of sudden death in asymptomatic patients with AAOCA. For decades, physicians and surgeons have attempted to risk-stratify patients. Nowadays, observation appears to be reasonable for asymptomatic patients with an AAOCA without ischemia, or physiological evaluation suggesting potential for coronary compromise. $^{6}$

Unfortunately, surgery is not without its risks. Jegatheeswaran and colleagues ${ }^{7}$ report a small $(10 \%)$, but not insignificant risk of developing new aortic regurgitation, particularly in patients who underwent commissural manipulation. Furthermore, $2 \%$ of patients developed a new decrease in ejection fraction following surgery. ${ }^{7}$ Of particular importance, $20 \%$ of patients had ongoing symptoms of ischemic chest pain. ${ }^{7}$ Thus, if a patient did not have any inducible symptoms on exercise testing, is it reasonable to observe these patients rather than to expose them to the risk of surgery, albeit small?

Patients presenting after hemodynamic collapse, with ischemic chest pain, or with a positive stress test should be offered surgery. It is clear what to do with these patients. It is not clear what to do with asymptomatic patients. Lifelong observation does not seem unreasonable. Or, do we offer surgery to address the lesion and potentially 


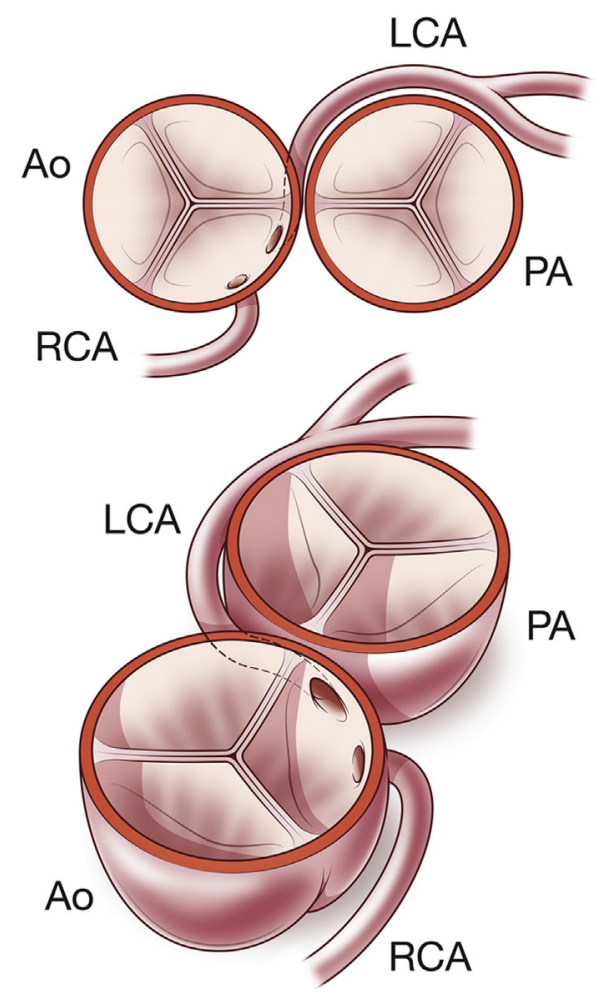

A

FIGURE 1. Anomalous aortic origin of the left (A) or right (B) coronary artery with an interarterial course. Ao, Aorta; $L C A$, left coronary artery; $P A$, pulmonary artery; $R C A$, right coronary artery.

introduce new cardiac complications? To do surgery, or not to do surgery? That is the question.

\section{References}

1. Brothers J, Carter C, McBride M, Spray T, Paridon S. Anomalous left coronary artery origin from the opposite sinus: evidence of intermittent ischaemia. J Thorac Cardiovasc Surg. 2010;2:27-9.

2. Basso C, Maron BJ, Carrado D, Thiene G. Clinical profile of congenital coronary artery anomalies with origin from the wrong aortic sinus leading to sudden death in young competitive athletes. J Am Coll Cardiol. 2000;35:1493-501.

3. Maron BJ, Doerer JJ, Haas TS, Tierney DM, Mueller FO. Sudden death in young competitive athletes. Circulation. 2009;119:1085-92.

4. Brothers JA, McBride MG, Seliem MA, Marino BS, Tomlinson RS, Pampaloni $\mathrm{MH}$, et al. Evaluation of myocardial ischemia after surgical repair of

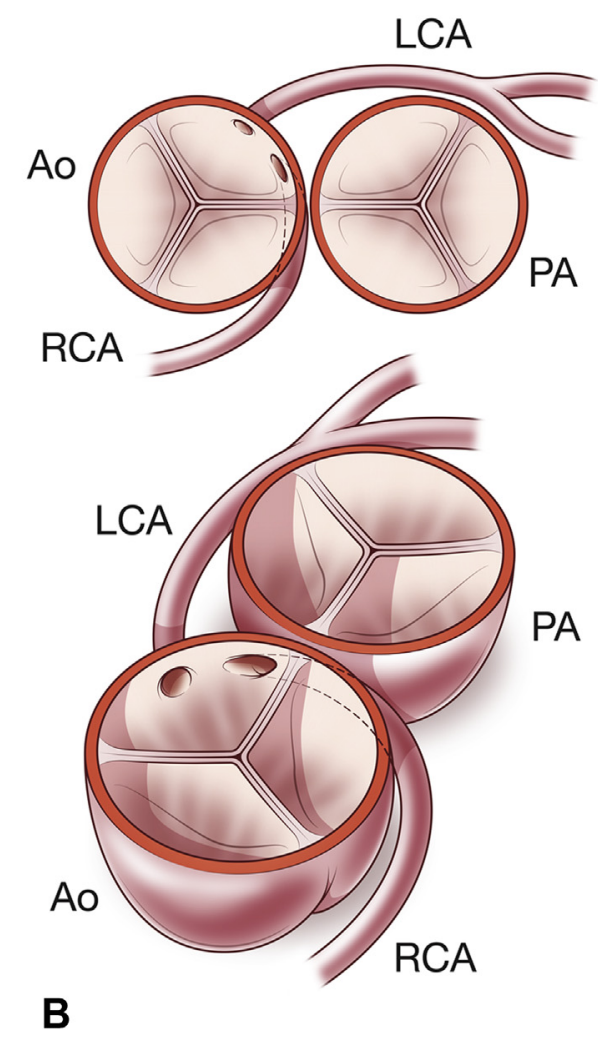

PA

anomalous aortic origin of a coronary artery in a series of pediatric patients. $J$ Am Coll Cardiol. 2007;50:2078-82.

5. Mery CM, De Leon LE, Molossi S, Sexon-Tejtel SK, Agrawal H, Krishnamurthy R, et al. Outcomes of surgical intervention for anomalous aortic origin of a coronary artery: a large contemporary prospective cohort study. $J$ Thorac Cardiovasc Surg. 2018;155:305-19.

6. Stout KK, Daniels CJ, Aboulhosn JA, Bozkurt B, Broberg CS, Colman JM, et al 2018 AHA/ACC guideline for the management of adults with congenital heart disease: a report of the American College of Cardiology/American Heart Association Task Force on Clinical Practice Guidelines. Circulation. 2019;139: 698-800.

7. Jegatheeswaran A, Devlin PJ, Williams WG, Brother JA, Jacobs ML, DeCampli WM, et al. Outcomes after anomalous aortic origin of a coronary artery repair: a Congenital Heart Surgeons' Society Study. J Thorac Cardiovasc Surg. 2020;160:757-71.e5. 